\title{
MESIN PANAS FOTO-CARNOT LUBANG HITAM NON-STASIONER
}

\section{NON-STATIONARY BLACK HOLE PHOTO-CARNOT HEAT ENGINE}

\author{
Yuant Tiandho \\ Jurusan Fisika, Universitas Bangka Belitung \\ email: yuant@ubb.ac.id
}

Diterima 19 Februari 2017, disetujui 29 Maret 2017

\begin{abstract}
Abstrak
Di dalam makalah ini disajikan suatu analisis teoritik dari desain mesin panas foto-Carnot dengan sumber energi berupa lubang hitam non-stasioner. Diharapkan dari kajian ini dapat diketahui potensi penggunaan lubang hitam sebagai sumber "bahan bakar" dari suatu mesin panas. Desain mesin panas berbasis lubang hitam dikembangkan karena melalui mekanika kuantum lubang hitam dapat mengemisikan partikel dan memiliki temperatur layaknya dalam proses radiasi benda hitam. Perhitungan temperatur lubang hitam non-stasioner yang meradiasikan foton dilakukan berdasarkan gambaran tunneling dengan menggunakan metode Hamilton-Jacobi. Sebagai hasilnya, lubang hitam non-stasioner memiliki temperatur yang juga bergantung terhadap laju perubahan massa. Desain mesin panas yang dikaji dalam makalah ini terdiri dari dua buah lubang hitam non-stasioner berbeda massa sehingga memiliki perbedaan tekanan radiasi yang dapat menggerakkan piston. Secara umum, efisiensi dari mesin foto-Carnot bergantung pada massa lubang hitam, laju perubahan massa, serta suatu fungsi penyeimbang dalam metrik Vaidya.

Kata kunci: mesin foto-Carnot, termodinamika lubang hitam, non-stasioner.
\end{abstract}

\section{Non-Stationary Black Hole Photo-Carnot Heat Engine}

\begin{abstract}
This paper presents a theoretical analysis of a photo-Carnot heat engine design with an energy source from a non-stationary black hole. This study may provide a clue about the potential use of black hole as a "fuel" of a heat engine. Heat engine design was developed because according to quantum mechanics a black hole may emit particles and it has temperature like in the black-body radiation. The calculation of nonstationary black hole temperature which radiate photons is based on the tunneling picture by using the Hamilton-Jacobi method. As a result, the temperature of non-stationary black hole also depends on the mass flow rate. The model of heat engine that studied in this work contains two non-stationary black holes with different masses that have different radiation pressure to move the piston. In general, the efficiency of photoCarnot engine depend on the mass of the black hole, the mass flow rate, and the balance function in the Vaidya metric.
\end{abstract}

Keywords: photo-Carnot engine, black hole thermodynamics, non-stationary.

\section{Pendahuluan}

Energi merupakan salah satu elemen krusial dalam proses pembangunan berkelanjutan di berbagai negara pada era moden. Lebih dari itu, energi merupakan salah satu kunci kehidupan di dunia. Seiring dengan penipisan jumlah sumber energi tak terbarukan maka isu penggunaan sumber energi terbarukan akhir-akhir ini semakin banyak dikaji [1]. Tetapi disadari atau tidak, berbagai sumber energi terbarukan yang sejauh ini diusulkan di kemudian hari tidak lagi dapat diperbarui.
Misalkan saja matahari, pada akhirnya matahari dan semua bintang akan kehabisan bahan bakar untuk dapat melakukan reaksi nukleosintesis. Jika hal itu terjadi, apakah kehidupan dapat terus berjalan? Dari manakah energi dapat diperoleh? Terlebih kita sebenarnya hidup di alam semesta yang mengembang dan suatu saat nanti alam semesta akan mengalami proses pendinginan universal. Dalam kondisi tersebut, ketika bintangbintang telah mati apakah ada sesuatu yang berfungsi sebagai sumber energi untuk melanjutkan kehidupan? [2]. 
Salah satu solusi yang mungkin dapat diterapkan untuk mengatasi permasalahan energi tersebut adalah melalui ekstraksi energi dari lubang hitam. Dengan menggunakan mekanika kuantum, Hawking telah menyimpulkan bahwa lubang hitam memiliki temperatur sebesar $[3,4]$,

$$
T=\frac{\hbar c^{3}}{8 \pi G M k_{B}}
$$

Selain itu Bekenstein juga telah memperoleh entropi dari lubang hitam terkait dengan luas area lubang hitam, $A$, itu sendiri $[5,6]$,

$$
S=\frac{c^{3} A}{4 G \hbar}
$$

Dari kedua aspek di atas tampak bahwa lubang hitam dapat dipandang sebagai suatu objek termodinamik. Lubang hitam secara mekanika kuantum tidak lagi menjadi objek termodinamika yang mati seperti dirumuskan dalam teori relativitas umum. Munculnya sifat-sifat termodinamika tersebut dikarenakan lubang hitam tidak hanya dapat mengabsorpsi partikel melainkan juga dapat mengemisikan partikel layaknya proses radiasi benda hitam.

Opatrny dan Richterek telah mengajukan sebuah model mesin panas yang tersusun dari dua buah lubang hitam berbeda ukuran dimana tiap lubang hitam terkurung dalam suatu kotak yang dihubungkan oleh piston silinder [7]. Karena ukuran lubang hitam dipengaruhi oleh massanya maka dapat diasumsikan bahwa kedua lubang hitam memiliki temperatur yang berbeda. Melalui pers. (1) dapat diketahui bahwa lubang hitam yang lebih kecil memiliki temperatur yang lebih panas dibandingkan yang lebih besar. Karena adanya perbedaan temperatur dari lubang hitam dan dengan sedikit rekayasa mekanisasi piston maka kondisi dari sistem dapat dimodelkan memenuhi siklus mesin panas.

Di dalam makalah ini akan dilakukan kajian mesin panas yang terbuat dari dua buah lubang hitam non-stasioner. Kajian ini dilakukan karena pada kajian yang dilakukan oleh Opatmy dan Ricterek digunakan lubang hitam Schwarzschild yang bersifat statis. Lubang hitam non-stasioner lebih realistis karena dapat memberikan gambaran yang lebih baik ketika mendeskripsikan proses evaporasi [8]. Adapun lubang hitam non-stasioner yang dipilih dalam makalah ini adalah lubang hitam Vaidya yang massanya secara implisit bergantung dengan ruang dan waktu. Selain itu, metrik Vaidya awalnya juga digunakan untuk membahas perilaku bintang yang meradiasi [9].

\section{Metode Penelitian}

Di dalam makalah ini desain mesin panas berbasis lubang hitam tersusun dari dua buah lubang hitam non-stasioner berbeda temperatur. Temperatur dan entropi dari lubang hitam nonstasioner dihitung berdasarkan gambaran tunneling dengan emisi partikel berupa foton. Adapun untuk mempermudah perhitungan kajian temperatur lubang hitam dilakukan dengan metode HamiltonJacobi. Sebelum diterapkan pada mesin panas variabel-variabel termodinamik dari lubang hitam diuji di dalam suatu kotak yang terisolasi. Adapun tujuan dari pengujian ini adalah untuk mengamati perilaku radiasi dari lubang hitam. Selanjutnya analisis mesin panas berbasis lubang hitam dilakukan berdasarkan aspek siklus termodinamik dan efisiensinya. Seluruh proses analisis dan perhitungan di dalam makalah dilakukan berdasarkan matematika analitik. Selanjutnya, untuk menyederhanakan proses perhitungan dalam makalah ini digunakan satuan natural unit.

\section{Hasil dan Pembahasan}

Berdasarkan metode yang telah diuraikan maka pembahasan hasil penelitian akan dibagi pada beberapa bagian sebagai berikut:

\section{A. Termodinamika Lubang Hitam}

Lubang hitam Vaidya adalah lubang hitam non-stasioner paling sederhana. Metrik lubang hitam Vaidya dapat dituliskan dalam koordinat $r-t$ dan $u-v$ dimana koordinat yang terakhir merupakan koordinat dengan transformasi Eddington-Finkelstein. Tetapi di dalam makalah ini digunakan ungkapan metrik dalam koordinat $r-t$ agar efek evaporasi tampak secara eksplisit. Metrik ruang waktu Vaidya dalam koordinat $r-t$ didefinisikan sebagai [10],

$$
d s^{2}=-\left(\frac{\dot{m}}{x(m)}\right)^{2}\left(1-\frac{2 m}{r}\right) d t^{2}+\left(1-\frac{2 m}{r}\right)^{-1} d r^{2}+r^{2} d \Omega^{2}
$$


dimana $d \Omega=d \theta^{2}+\sin ^{2} \theta d \varphi^{2}$. Pada metrik di atas massa lubang hitam merupakan fungsi dari koordinat $r$ dan waktu $t, m \equiv m(r, t)$ sehingga tampak bahwa dalam metrik ini lubang hitam yang dikaji merupakan lubang hitam non-stasioner. Suku $x(m)$ adalah fungsi sebarang yang bergantung pada model lubang hitam yang digunakan. Tetapi secara umum suku $x(m)$ merupakan fungsi dari massa lubang hitam. Selanjutnya tanda titik, misal pada $\dot{m}$, menunjukkan turunan terhadap waktu sedangkan tanda aksen, misal $m$ ', menunjukkan turunan terhadap koordinat $r$. Karena massa bergantung pada $r$ dan $t$ serta $x$ merupakan fungsi dari $m$ maka metrik pada pers. (3) memiliki bentuk umum sebagai [11],

$$
d s^{2}=-F(r, t) d t^{2}+G(r, t)^{-1} d r^{2}+r^{2} d \Omega^{2}
$$

dengan koefisien $F(r, t) \equiv \dot{m}^{2}(1-2 m / r) / x(m)^{2}$ dan $G(r, t) \equiv 1-2 m / r$. Untuk meringkas penulisan maka selanjutnya fungsi $x(m), F(r, t)$, dan $G(r, t)$ hanya dituliskan sebagai $x, F$, dan $G$.

Kajian radiasi Hawking oleh lubang hitam dengan partikel emisi foton sebelumnya telah dilakukan oleh Majhi dan Samanta [12], tetapi kajian tersebut dilakukan untuk lubang hitam stasioner Schwarzschild. Medan elektromagnetik dengan latar gravitasi diberikan oleh Lagrangian,

$$
L=-\frac{1}{4} \sqrt{-g} F_{\mu v} F^{\mu \nu}
$$

Dimana kuat medan $F_{\mu \nu}$ didefinisikan oleh medan gauge $A_{\mu}$ sebagai,

$$
F_{\mu \nu}=\nabla_{\mu} A_{v}-\nabla_{v} A_{\mu}
$$

Berdasarkan rumusan Lagrangian pada pers. (5) maka dapat aksi dari medan elektromagnetik akan memenuhi,

$$
S=-\frac{1}{4} \int F_{\mu \nu} F^{\mu v} \sqrt{-g} d^{4} x
$$

Bedasarkan prinsip variasi $A_{\mu}$ dalam aksi di atas akan diperoleh persamaan gerak,

$$
\nabla^{\mu} F_{\mu \nu}=0
$$

Sehingga dengan menggunakan definisi turunan kovarian dari medan tensor, pers. (8) dapat dituliskan sebagai,

$$
g^{v \alpha}\left(\partial_{\alpha} F_{\mu v}-\Gamma_{\alpha \mu}^{\lambda} F_{\lambda v}-\Gamma_{\alpha \nu}^{\lambda} F_{\mu \lambda}\right)=0
$$

Berdasarkan metode Hamilton-Jacobi, medan vektor $A_{\mu}$ secara ansatz dapat dinyatakan sebagai,

$$
A_{\mu}=a_{\mu} e^{-\frac{i}{\hbar} S(t, r, \theta, \varphi)}
$$

dimana $a_{\mu}$ adalah vektor polarizasi yang tidak bergantung pada koordinat ruang-waktu dan $S$ adalah fungsi aksi sesuai dengan yang dituliskan di atas. Seperti biasa, aksi dapat diuraikan sebagai deret konstanta Planck,

$$
S(t, r, \theta, \varphi)=S_{0}(r, t, \theta, \varphi)+\sum_{i=1}^{\infty} \hbar^{i} S_{i}(t, r, \theta, \varphi)
$$

Karena dalam tinjuan kali ini tidak dilakukan koreksi kuantum yang ketat maka vektor polarisasi tidak perlu diuraikan dalam deret konstanta Planck seperti dilakukan pada [12]. Dengan melakukan substitusi pers.

Error! Reference source not found. ke dalam pers. (9) dan dengan mengambil limit nilai konstanta Planck yang sangat kecil, $\hbar \rightarrow 0$, maka akan diperoleh,

$$
g^{\rho \sigma} a_{\mu 0}\left(\partial_{\rho} S_{0}\right)\left(\partial_{\sigma} S_{0}\right)=0
$$

Tetapi karena lubang hitam Vaidya bersifat simetri bola maka pers. (12) akan mereduksi pada kasus dua dimensi saja: koordinat $r$ dan $t$ sehingga,

$$
g^{t t}\left(\partial_{t} S_{0}\right)^{2}+g^{r r}\left(\partial_{r} S_{0}\right)^{2}=0
$$

dan menghasilkan,

$$
\partial_{r} S_{0}= \pm \frac{1}{\sqrt{F G}} \partial_{t} S_{0}
$$

Tanda plus dan minus pada persamaan di atas berkaitan dengan jenis partikel yang datang dan meninggalkan lubang hitam. Berdasarkan metode Hamilton-Jacobi, aksi pada pers. (14) dapat diungkapkan dalam dua komponen: komponen energi-waktu yang memiliki bentuk $E t$ dan komponen radial yang dituliskan sebagai $R(r, t)$ [8], 


$$
S_{0}=-\int_{0}^{t} E\left(t^{\prime}\right) d t^{\prime}+R(r, t)
$$

Ungkapan $\int_{0}^{t} E\left(t^{\prime}\right) d t^{\prime}$ pada uraian fungsi di atas digunakan agar dapat mengakomodir kondisi lubang hitam yang bersifat non-stasioner sehingga dimungkinkan adanya energi yang dapat bervariasi terhadap waktu. Dari persamaan di atas dapat diturunkan ungkapan turunan aksi terhadap $t$ dan $r$ masing-masing sebagai,

$$
\begin{gathered}
\partial_{t} S_{0}=E(t)+\partial_{t} R(r, t) \\
\partial_{r} S_{0}=\partial_{r} R(r, t)
\end{gathered}
$$

Sehingga berdasarkan aturan rantai juga diizinkan untuk menuliskan,

$$
\frac{d R}{d r}=\partial_{r} R(r, t)+\partial_{t} R(r, t) \frac{d t}{d r}
$$

Pada metrik simetri bola dengan bentuk seperti pada pers. (4), kondisi radial null geodesic akan memberikan kesimpulan bahwa [11],

$$
\frac{d t}{d r}= \pm \frac{1}{\sqrt{F G}}
$$

Sehingga dengan melakukan kombinasi pers. (14), (16), (17), (18), dan (19) akan diperoleh persamaan diferensial dari $R(r, t)$ sebagai,

$$
\frac{d R}{d r}= \pm \frac{1}{\sqrt{F G}} E(t)
$$

Solusi dari komponen radial aksi dapat diperoleh melalui integrasi,

$$
R(r, t)= \pm E(t) \int \frac{d r}{\sqrt{F G}}
$$

Karena radiasi Hawking terjadi pada horizon lubang hitam, terlepas dari perdebatan apakah di event horizon atau apparent horizon, maka koefisien metrik $F$ dan $G$ dapat diuraikan berdasarkan deret Taylor di sekitar horizonnya pada waktu yang tetap,

$$
\begin{aligned}
& \left.\left.F\left(r_{h}, t\right)\right|_{t} \approx F^{\prime}\left(r_{h}, t\right)\right|_{t}\left(r-r_{h}\right)+\left.O\left(r-r_{h}\right)^{2}\right|_{t} \\
& \left.\left.G\left(r_{h}, t\right)\right|_{t} \approx G^{\prime}\left(r_{h}, t\right)\right|_{t}\left(r-r_{h}\right)+\left.O\left(r-r_{h}\right)^{2}\right|_{t}
\end{aligned}
$$

Sehingga integrasi pada pers. (21) dapat dituliskan sebagai,

$$
R(r, t)= \pm \lim _{\delta \rightarrow 0}\left(\frac{E(t)}{\sqrt{F^{\prime}\left(r_{h}, t\right) G^{\prime}\left(r_{h}, t\right)}} \int_{r_{h}-\delta}^{r_{h}+\delta} \frac{d r}{r-r_{h}}\right)
$$

Integrasi di atas dapat diselesaikan dengan menggunakan integrasi biasa melalui penerapan identitas Euler, $e^{i \pi}+1=0$, sehingga solusi dari komponen radial aksi secara eksplisit adalah,

$$
R(r, t)= \pm \frac{i \pi E(t)}{\sqrt{F^{\prime}\left(r_{h}, t\right) G^{\prime}\left(r_{h}, t\right)}}
$$

Dengan demikian melalui substitusi ungkapan komponen radial aksi pada (15) dan definisi medan vektor pada (10) maka probabilitas dari partikel yang menuju dan meninggalkan lubang hitam dapat ditentukan, $\quad P=\left|A^{\mu}\right|^{2}$. Melalui asumsi bahwa seluruh partikel yang menuju lubang hitam akan terabsorp sempurna atau $P_{i n}=1$ maka probabilitas partikel yang meninggalkan lubang hitam dapat diungkapkan sebagai,

$$
\begin{aligned}
P_{\text {out }} & =P_{\text {in }} \exp \left(-\frac{4 E(t)}{\hbar \sqrt{F^{\prime}\left(r_{h}, t\right) G^{\prime}\left(r_{h}, t\right)}}\right) \\
& =\exp \left(-\frac{4 E(t)}{\hbar \sqrt{F^{\prime}\left(r_{h}, t\right) G^{\prime}\left(r_{h}, t\right)}}\right)
\end{aligned}
$$

Dalam gambaran tunneling, probabilitas partikel emisi dapat dikaitkan dengan rumusan faktor Boltzman, $\beta$, dan energinya sebagai, $P_{\text {out }}=\exp (-E \beta)$. Sehingga temperatur lubang hitam Vaidya akibat mengemisikan foton adalah,

$$
T=\frac{\hbar \sqrt{F^{\prime}\left(r_{h}, t\right) G^{\prime}\left(r_{h}, t\right)}}{4 \pi}
$$

Dapat dilihat bahwa rumusan temperatur Hawking akibat emisi foton pada pers. (26) secara umum selain bergantung pada radius horizon juga bergantung pada waktu. Berdasarkan ungkapan koefisien metrik pada pers. (3) dengan menggunakan aturan turunan parsial dengan mudah dapat dinyatakan bahwa,

$$
F^{\prime}=\frac{2 \dot{m}}{x^{2}}\left(\dot{m}^{\prime}\left(1-\frac{2 m}{r}\right)+\dot{m}\left(\frac{m}{r^{2}}-\frac{m^{\prime}}{r}\right)-\frac{\dot{m} x^{\prime}}{x}\left(1-\frac{2 m}{r}\right)\right)
$$




$$
G^{\prime}=\frac{2 m}{r^{2}}-\frac{2 m^{\prime}}{r}
$$

Sehingga dengan mengingat horizon $r_{h}=2 \mathrm{~m}$ maka temperatur lubang hitam Vaidya secara eksplisit dapat diungkapkan sebagai,

$$
T=\frac{\hbar \dot{m}}{4 \pi x}\left(\frac{1}{2 m}-\frac{m^{\prime}}{m}\right)
$$

Pada rumusan temperatur di atas tampak bahwa secara eksplisit temperatur lubang hitam Vaidya akibat emisi foton bergantung pada laju perubahan massa. Namun demikian, rumusan tersebut akan mereduksi pada temperatur lubang hitam statis ketika dipenuhi limit $x \rightarrow \dot{m}$ dan $m^{\prime} \rightarrow 0$.

Berdasarkan hukum pertama termodinamika lubang hitam untuk lubang hitam Vaidya yang tidak berotasi dan bermuatan dipenuhi,

$$
d m=T d S
$$

Sehingga entropi dari lubang hitam dapat ditentukan sebagai,

$$
S=\int \frac{4 \pi x d m}{\hbar \dot{m}\left(\frac{1}{2 m}-\frac{m^{\prime}}{m}\right)}
$$

Untuk memperoleh ungkapan entropi lubang hitam Vaidya secara eksplisit dibutuhkan informasi dari variabel $\dot{m}, m^{\prime}$, dan $x$ secara eksplisit pula. Tanpa informasi variabel tersebut maka ungkapan entropi secara eksplisit juga tidak dapat diperoleh. Tetapi meskipun demikian, ungkapan entropi pada pers. (31) menyatakan ungkapan entropi lubang hitam Vaidya secara umum.

\section{B. Radiasi Lubang Hitam dalam Kotak}

Seperti dinyatakan sebelumnya, model mesin panas yang akan dikaji dalam makalah ini merujuk pada model mesin panas yang diajukan oleh Opatrny dan Richterek [7]. Dalam model ini lubang hitam diletakkan pada suatu kotak yang dengan sempurna merefleksikan foton dan kotak tersebut terisolasi dari dunia luar sehingga total energi dalam sistem bernilai konstan. Karena lubang hitam dapat meradiasikan foton dengan temperatur dan entropi yang nilainya seperti diungkapkan pada pers. (29) dan (31) maka mesin panas dapat diasumsikan melakukan siklus foto-Carnot. Dalam siklus foto-Carnot radiasi dipandang sebagai kerja fluida dan piston yang bekerja dalam sistem dikendalikan oleh tekanan radiasi.

Sebelum membahas tentang perilaku siklus foto-Carnot dari mesin panas lubang pada bagian ini akan didiskusikan perilaku lubang hitam yang diisolasi dalam kotak terlebih dahulu. Ketika suatu lubang hitam bermassa $m$ dan bertemperatur $T$ diletakkan dalam sebuah kotak bervolume $V$ dalam kondisi kesetimbangan termodinamik maka total energi dari lubang hitam tersebut dapat dinyatakan sebagai [7],

$$
E_{\text {tot }}=m+a \varepsilon V T^{4}
$$

Pada persamaan di atas $a$ adalah konstanta yang berkaitan dengan konstanta Stefan-Boltzmann dan $\varepsilon$ adalah konstanta emistivitas. Karena lubang hitam dipandang sebagai benda hitam sempurna maka dapat diasumsikan, $\varepsilon=1$. Dapat dilihat bahwa energi pada suku pertama pers. (32) merupakan energi yang berasal dari hubungan energi-massa lubang hitam sedangkan suku kedua berkaitan dengan energi internal atau energi radiasi pada mesin foto-Carnot. Karena sistem kotak merupakan sistem terisolasi maka tentu energi yang dihasilkan oleh proses radiasi berkaitan erat dengan massa lubang hitam. Misalkan, lubang hitam mengalami pengurangan massa akibat proses radiasi maka hal ini akan menyebabkan pertambahan nilai pada suku yang berkaitan dengan energi internal. Hal ini juga sesuai dengan ungkapan dari temperatur Hawking pada pers. (29) yang berbanding terbalik terhadap massa. Secara eksplisit, dengan mengasumsikan perubahan massa lubang hitam akibat radiasi bernilai konstan dan volume kotak tidak berubah maka energi total sistem dapat diungkapkan sebagai,

$$
E_{t o t}=\int \dot{m} d t+a V\left(\frac{\hbar \dot{m}}{4 \pi x}\left(\frac{1}{2 m}-\frac{m^{\prime}}{m}\right)\right)^{4}
$$

Karena energi total sistem bersifat kekal maka dipenuhi kondisi, $d E / d t=0$. Sehingga berdasarkan hal tersebut dapat diperoleh nilai $x$ yang mungkin ketika dipenuhi kondisi $\dot{m}=$ konstan sebagai, 


$$
x= \pm \frac{1}{16 \pi m^{2} \dot{m}}\left( \pm \sqrt{\left(a \hbar V\left(32 \pi m^{3}\left(-1+2 m^{\prime}\right) \dot{m}^{2} \dot{x}+a \hbar V\left(\begin{array}{l}
\left(-1+2 m^{\prime}\right) \dot{m}^{2}- \\
2 m \dot{m} \dot{m}^{\prime}+m\left(1-2 m^{\prime}\right) \ddot{m}
\end{array}\right)\right)\right.}\right)
$$

Entropi sistem lubang hitam dalam kotak ketika meradiasikan foton dapat diungkapkan sebagai,

$$
S_{t o t}=\int \frac{4 \pi x d m}{\hbar \dot{m}\left(\frac{1}{2 m}-\frac{m^{\prime}}{m}\right)}+\frac{4}{3} a V T^{3}
$$

Suku pertama dari ungkapan di atas berkaitan dengan entropi lubang hitam sendiri sedangkan suku kedua berkaitan dengan entropi radiasi. Pada kasus limit lubang hitam statis (Schwarzschild) maka ungkapan entropi di atas akan mereduksi

pada ungkapan entropi yang diperoleh dalam [7]. Pada analisis limit statis, [7] telah memperoleh bahwa ukuran kotak maksimum agar sistem ini memenuhi kesetimbangan termal adalah,

$$
l_{\text {kotak }} \leq 40 l_{p}\left(\frac{m}{m_{p}}\right)^{5 / 3}
$$

dimana $l_{p}$ adalah panjang Planck dan $m_{p}$ adalah massa Planck.

\section{Mesin foto-Carnot Lubang Hitam}

Skema ekstraksi energi lubang hitam melalui siklus foto-Carnot yang dibahas dalam makalah ini ditunjukkan pada Gambar 1. Dua buah lubang hitam masing-masing diletakkan pada suatu kotak yang terisolasi dari dunia luar dan dihubungkan oleh piston yang dapat bergerak akibat tekanan radiasi. Volume silinder piston jauh lebih kecil dibanding volume kotak yang berisi lubang hitam. Agar mesin panas dapat bekerja maka dibutuhkan dua "reservoir" yang memiliki perbedaan temperatur.

Reservoir dengan temperatur lebih tinggi akan membuat piston bergerak menuju ke reservoir dengan temperatur lebih rendah. Oleh karena itu, setidaknya sistem mesin panas lubang hitam haruslah terdiri dari dua lubang hitam yang berbeda temperatur. Melalui pers. (29) dapat dilihat bahwa temperatur lubang hitam berbanding terbalik dengan massanya. Sehingga reservoir panas dapat dibuat dengan cara me lebih kecil (sehingga horizonnya juga lebih kecil) sedangkan untuk reservoir dingin dengan kondisi sebaliknya.
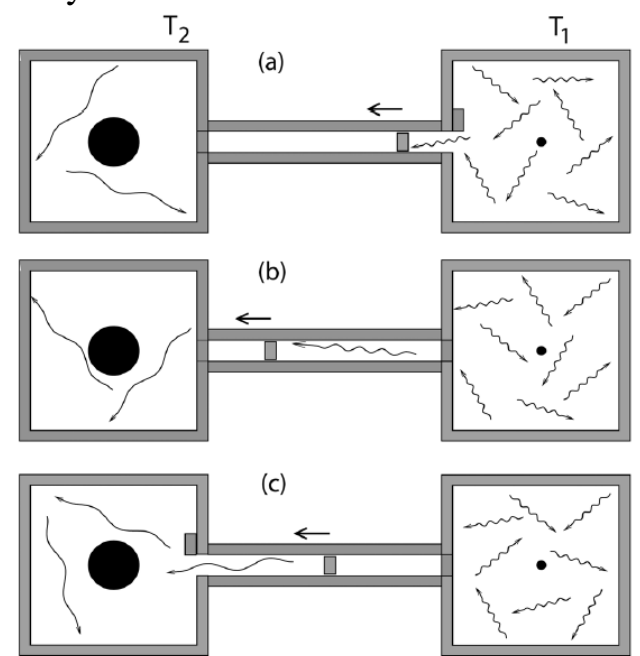

Gambar 1. Skema mesin foto-Carnot dari dua buah lubang hitam berbeda temperatur. Lubang hitam besar memiliki temperatur lebih rendah dari lubang hitam kecil. Siklus mesin panas: (a) radiasi dari lubang hitam kecil masuk ke dalam silinder dan mendorong piston ke lubang hitam besar, (b) silinder terisolasi dan piston bergerak secara adiabatik, (c) radiasi tersebut mendingin dan masuk ke dalam kotak berisi lubang hitam besar secara isotermik-isobarik [7].

Secara terperinci siklus mesin panas ini adalah sebagai berikut: (a) pada tahapan pertama silinder penghubung di sisi reservoir panas akan terbuka dan piston akan bergerak sehingga volume silinder "kerja" akan meningkat sebesar $d V_{a}$. Dalam mesin foto-Carnot, piston akan terdorong oleh tekanan radiasi yang nilainya sebanding dengan pangkat empat temperatur, $p=\varepsilon a T^{4} / 3=a T^{4} / 3, \quad$ sehingga berdasarkan definisi temperatur pada pers. (29) diperoleh,

$$
p_{1}=\frac{a \hbar^{4}}{768 \pi^{4} x_{1}^{4}}\left(\dot{m}_{1}\left(\frac{1}{2 m_{1}}-\frac{m_{1}^{\prime}}{m_{1}}\right)\right)^{4}
$$

Indeks 1 dalam persamaan di atas dan selanjutnya berkaitan dengan variabel untuk lubang hitam panas dan 2 berkaitan dengan lubang hitam dingin. Yang menarik dari persamaan di atas adalah tekanan radiasi yang dihasilkan secara umum juga bergantung terhadap waktu. Sehingga definisi penggunaan ungkapan reservoir dalam mesin panas lubang hitam secara umum berkaitan 
dengan reservoir yang bersifat dinamis. Karena pada kenyataannya ketika lubang hitam meradiasi maka massanya akan berkurang. Namun demikian, untuk tinjauan radiasi foton seperti yang dilakukan dalam makalah ini, karena "massa" partikel emisi jauh lebih kecil dari massa lubang hitam itu sendiri maka asumsi ungkapan reservoir yang umum dalam desain mesin panas masih dapat diterapkan.

Berdasarkan rumusan tekanan radiasi yang hanya bergantung pada temperatur maka dapat disimpulkan bahwa jika pada tahapan pertama siklus mesin panas terjadi secara isotermik maka tahapan ini juga memenuhi kondisi isobarik. Dengan demikian kerja yang dilakukan akibat ekspansi sebesar $d V_{a}$ adalah,

$$
d W_{a}=\frac{a \hbar^{4}}{768 \pi^{4} x_{1}^{4}}\left(\dot{m}_{1}\left(\frac{1}{2 m_{1}}-\frac{m_{1}{ }^{\prime}}{m_{1}}\right)\right)^{4} d V_{a}
$$

Berdasarkan hukum termodinamika pertama, $d E=d W+d Q$, dengan total energi yang terdapat dalam sebuah reservoir seperti dinyatakan dalam pers. (32) maka dapat dihitung besarnya energi yang diekstraksi akibat radiasi, $d Q$, pada tahapan ini adalah,

$$
d Q_{a}=\frac{a \hbar^{4} \dot{m}_{1}^{4}}{192 \pi^{4} x_{1}^{4}}\left(\frac{1}{2 m_{1}}-\frac{m_{1}^{\prime}}{m_{1}}\right) d V_{a}
$$

Dalam limit statik, ungkapan ini sama seperti pada [7] berdasarkan kalkulasi, $Q=T_{1} \Delta S_{1}$. Perhitungan pada persamaan di atas tidak melibatkan ekstraksi energi akibat perubahan massa lubang hitam dikarenakan pada lubang hitam dengan emisi foton partikel emisinya sangat kecil sehingga efek ekstraksi energi akibat kaitan massa-energi jauh lebih kecil dibandingkan efek radiasinya.

(b) Pada tahapan kedua, piston akan mulai bergerak kearah reservoir dingin sehingga menyebabkan volume kerja akan terekspansi lebih lanjut. Karena silinder piston terisolasi maka proses ekspansi terjadi secara adiabatik. Melalui ungkapan energi radiasi dengan menggunakan aturan rantai akan diperoleh, $d E=a T^{4} d V+4 a V T^{3} d T \quad$ sedangkan melalui ungkapan kerja radiasi yang memenuhi, $d W_{V}=\frac{1}{3} a T^{4} d V$ maka dapat disimpulkan jika sistem mengalami ekspansi adiabatik akan diperoleh, $V / T=$ konstan . Dengan demikian, apabila volume kerja piston ketika menuju resevoir dingin adalah $V_{b}$ maka hubungan antara $V_{a}$ dan $V_{b}$ diberikan oleh,

$$
V_{b}=V_{a}\left(T_{1} / T_{2}\right)
$$

Sehingga kerja yang dilakukan oleh sistem pada tahapan ini memenuhi,

$$
d W_{b}=a T_{1}^{4}\left(1-\frac{T_{2}}{T_{1}}\right) d V_{a}
$$

(c) Pada tahapan ketiga radiasi akan masuk ke dalam reservoir dingin secara isotermikisobarik. Karena radiasi masuk ke dalam reservoir dingin maka kerja,

$$
d W_{c}=-p_{2} d V_{b}
$$

Melalui hubungan $V_{a}$ dengan $V_{b}$ seperti pada pers. (40) maka kerja dan perubahan kalor sistem juga dapat dinyatakan sebagai,

$$
d W_{c}=-\frac{1}{3} a\left(\frac{\hbar \dot{m}_{2}}{4 \pi x_{2}}\left(\frac{1}{2 m_{2}}-\frac{m_{2}{ }^{\prime}}{m_{2}}\right)\right)\left(\frac{\hbar \dot{m}_{1}}{4 \pi x_{1}}\left(\frac{1}{2 m_{1}}-\frac{m_{1}{ }^{\prime}}{m_{1}}\right)\right)^{3} d V_{a}
$$

$$
d Q_{c}=\frac{4}{3} a\left(\frac{\hbar \dot{m}_{2}}{4 \pi x_{2}}\left(\frac{1}{2 m_{2}}-\frac{m_{2}{ }^{\prime}}{m_{2}}\right)\right)\left(\frac{\hbar \dot{m}_{1}}{4 \pi x_{1}}\left(\frac{1}{2 m_{1}}-\frac{m_{1}{ }^{\prime}}{m_{1}}\right)\right)^{3} d V_{a}
$$

(d) Pada tahapan terakhir sistem mesin panas akan kembali ke siklus semula tanpa ada ekspansi volume kerja sehingga tidak ada kerja yang dilakukan oleh sistem. Dengan demikian, total kerja yang dilakukan dalam satu siklus mesin foto-

Carnot lubang hitam non-stasioner memenuhi, $\quad W=W_{a}+W_{b}+W_{c}=Q_{a}-Q_{c} . \quad$ Dari kaitan tersebut dapat dihitung efisiensi dari mesin panas sebagai,

$$
\eta=\frac{W}{Q_{a}}=1-\frac{T_{2}}{T_{1}}
$$

Sehingga berdasarkan ungkapan kerja dan kalor yang bergantung pada koordinat $r$ dan $t$ maka efisiensi secara eksplisit dapat diungkapkan dalam, 


$$
\eta=1-\left(\frac{m_{1}^{2} m_{2} \dot{m}_{1} x_{1}-2 m_{2} m_{1}{ }^{\prime} \dot{m}_{1} x_{1}}{m_{1} m_{2}^{2} \dot{m}_{2} x_{2}-2 m_{1} m_{2}{ }^{\prime} \dot{m}_{2} x_{2}}\right)
$$

Tampak bahwa secara eksplisit efisiensi lubang hitam dalam makalah ini bergantung pada waktu. Hal ini dapat dipahami karena pada dasarnya temperatur lubang hitam bergantung pada massa lubang hitam yang bersifat nonstasioner. Adapun hubungan antara efisiensi dengan massa lubang hitam dan laju perubahan massa lubang hitam per satuan waktu dapat dilihat pada Gambar 2(a) sedangkan hubungan antara efisiensi dengan faktor pangkat $x$ pada Gambar 2(b). Dengan menerapkan syarat batas $x_{1}$ $=x_{2}=m_{1}=d m_{1} / d t=1 \mathrm{dan} d m_{1} / d r=d m_{2} / d r=m^{2}$ dapat dilihat bahwa semakin besar nilai $\dot{m}_{2}$ maka semakin tinggi pula efisiensinya. Selain itu dari hubungan efisiensi dengan massa $m_{2}$ dapat dilihat bahwa ketika $m_{2}>m_{1}$ maka semakin besar $m_{2}$ semakin tinggi pula efisiensinya. Hal ini dapat dipahami melalui hubungan antara temperatur lubang hitam dengan massanya yang saling berbanding terbalik. Adapun ketika $m_{2}<m_{1}$ efisiensi dari mesin panas akan bernilai negatif. Kesimpulan ini dapat diperoleh karena jika $m_{2}<$ $m_{1}$ maka $T_{2}>T_{1}$ sehingga siklus tahapan mesin foto-Carnot mengalami kebalikan proses. Piston akan bergerak dari reservoir $m_{2}$ menuju resevoir $m_{1}$. Dengan menyatakan bentuk variabel $x_{2}=m_{2}{ }^{N}$ dapat dilihat bahwa faktor pangkat $N$ tidak memberikan efek yang begitu signifikan dibandingkan variasi massanya.

\section{Simpulan}

Melalui gambaran tunneling dengan metode Hamiltorn-Jacobi dapat diketahui bahwa ketika lubang hitam non-stasioner mengemisikan foton maka temperaturnya selain bergantung pada massa lubang hitam itu sendiri tapi juga bergantung pada laju perubahan massa lubang hitam. Dengan menggunakan dua buah lubang hitam yang berbeda massa maka mesin panas foto-Carnot dapat dijalankan karena adanya perbedaan temperatur dari lubang hitam tersebut. Siklus foto-Carnot yang dapat terdiri dari proses isotermik-isobarik, adiabatik, dan kembali pada isotermik-isobarik. Yang membedakan mesin foto-Carnot dalam makalah ini dengan yang lainnya adalah variabel-variabel mesin panas lubang hitam dapat dinyatakan sebagai fungsi waktu secara eksplisit. Efisiensi mesin foto-
Carnot yang diperoleh analogi dengan mesin Carnot konvensional. Semakin besar perbandingan $m_{2}$ terhadap $m_{1}$ maka semakin tinggi efisiensi mesin Carnot yang dihasilkan. Begitu pula dengan perbandingan $\dot{m}_{2}$ terhadap $\dot{m}_{1}$, semakin besar nilai $\dot{m}_{2}$ maka semakin tinggi pula efisiensinya. Adapun varibel $x$ yang bergantung pada massa lubang hitam tidak memberikan kontribusi yang begitu signifikan.

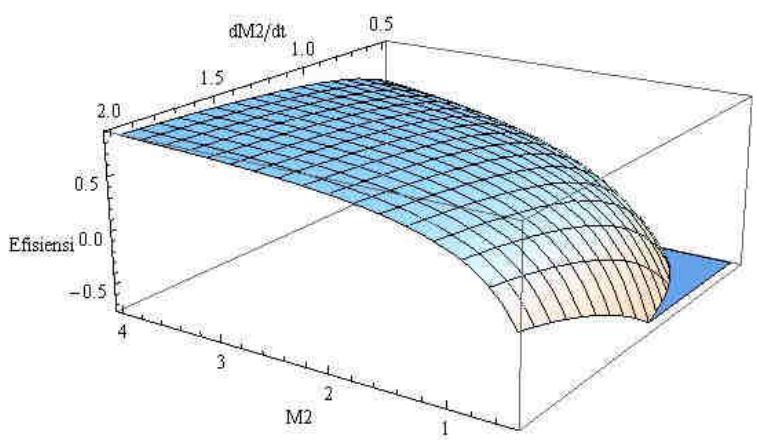

(a)

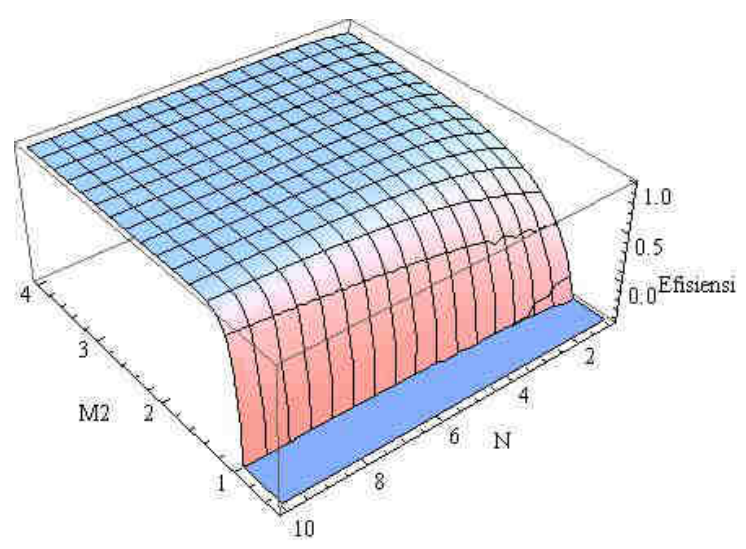

(b)

Gambar 2. Grafik hubungan antara efisiensi mesin foto-Carnot terhadap: (a) $m_{2}$ dan $d m_{2} / d t$ $\left(x_{1}=x_{2}=m_{1}=d m_{1} / d t=1\right.$ dan $d m_{1} / d r=$ $\left.d m_{2} / d r=m^{2}\right)$ dan (b) $m_{2}$ dan pangkat $N$ pada $x_{2}\left(x_{1}=m_{1}=d m_{1} / d t=d m_{2} / d t=1\right.$; $\left.d m_{1} / d r=d m_{2} / d r=m^{2} ; x_{2}=m_{2}^{N}\right)$.

\section{Ucapan Terima Kasih}

Penulis mengucapkan terima kasih kepada Fitri Afriani (Pusat Penelitian Fisika, LIPI Serpong) atas diskusi yang telah dilakukan. Penulis juga berterima kasih kepada Jurusan Fisika Universitas Bangka Belitung yang telah mendukung penelitian ini.

\section{Pustaka}


[1] Y. He, Y. xu, Y. Pang, H. Tian and R. Wu, (2016), A regulatory policy to promote renewable energy consumption in China: Review and future evolutionary path, Renewable Energy 89, 695-705.

[2] L. Krauss and G. Starkman, (2000), Life, the universe, and nothing: life and death in an ever-expanding universe," Astron. J. 531, 2230.

[3] S. W. Hawking, (1974), Black hole explosions?, Nature 248, 30-31.

[4] S. W. Hawking, (1975), Particle Creation by Black Holes, Commun. Math Phys. 43, 199220.

[5] J. D. Bekenstein, (1973), Black holes and entropy, Physical Review D 7(8), 2333-2346.

[6] J. D. Bekenstein, (1974), Generalized second law of thermodynamics in black-hole physics, Physical Review D 9(12), 32923300 .
[7] T. Opatrny and L. Richterek, (2012), Black hole heat engine, Am. J. Phys. 80(1), 66-71.

[8] Y. Tiandho and Triyanta, (2016), Dirac particles emission from Reissner-NordstromVaidya black hole, Journal of Physics Conference Series,739(1), 012146.

[9] P. C. Vaidya, (1951), The gravitational field of a radiating star, Proceeding of the Indian Academy of Sciences: A 33(5), 264-276.

[10] A. Farley and P. D'Eath, (2006), Vaidya space-time in black hole evaporation, Gen. Rel. Grav. 38, 425.

[11] H. M. Siahaan and Triyanta, (2010), Semiclassical method for Hawking radiation from a Vaidya blackhole, Int. J. Mod. Phys. A 25, 145-153.

[12] B. Majhi and S. Samanta, (2010), Hawking radiation due to photon and gravitino tunneling, Annals Phys. 325, 2410-2424. 